\title{
PENETAPAN RHODAMIN B PADA SAMPEL LIPSTIK DENGAN MENGGUNAKAN KLT- SPEKTROFOTODENSITOMETRI
}

\author{
N.N.A.S. Devi, N.P.M.P.P. Winarni, , I.P. Priyasana, G.A.D. Mayagita, V. Rahmadinha, K.M. \\ Limba, A.A.I.K. Dewi, I K.N. Sanjaya, N.P.L. Laksmiani \\ Program Studi Farmasi Fakultas Matematika dan Ilmu Pengetahuan Alam Universitas Udayana, \\ Jimbaran, Badung, Indonesia \\ *Email: satvika.devi@student.unud.ac.id
}

\begin{abstract}
ABSTRAK
Lipstik merupakan salah satu produk kosmetika dekoratif dan digunakan perempuan untuk mempercantik diri. Warna yang paling diminati adalah lipstik berwarna merah. Rhodamin B, salah satu zat warna sintetik yang tidak diperbolehkan penggunaannya dan digolongkan ke dalam bahan berbahaya pada Peraturan Menteri Kesehatan RI No.376/Menkes/Per/1990 karena dapat menyebabkan rusaknya hati, ginjal dan limfa serta menimbulkan pembesaran organ. Tujuan dari penelitian ini adalah untuk identifikasi dan analisis kuantitatif kandungan rhodamin pada lipstik yang ada di pasaran. Sampel lipstik dibeli pada 3 toko di Kota Denpasar dan Kabupaten Badung. Sampel direndam dengan larutan amonia bersama dengan benang wol untuk menarik zat rhodamin B dan diidentifikasi menggunakan plat KLT silika gel GF254 dengan fase gerak n-butanol: etil asetat: amonia (13,2:5,2:6,5) kemudian dideteksi dengan lampu UV $254 \mathrm{~nm}$ dan $366 \mathrm{~nm}$. Identifikasi dengan spektrofotodensitometri dan plat KLT diamati pada TLC Analyzer untuk diamati AUC pada masing-masing spot yang terbentuk. AUC yang diperoleh dari instrumen tersebut menggambarkan konsentrasi analit pada masingmasing totolan. Hasil penelitian menunjukkan bahwa 3 sampel yang diperiksa tidak teridentifikasi adanya pewarna sintetik rhodamin B.
\end{abstract}

Kata kunci: Rhodamin B, Lipstik, KLT, Spektrofotodensitometri

\begin{abstract}
Lipsticks are widely used by women to beautify themselves. Among the various colors that make lipstick more interesting, red color lipstick is the most demanded one. Rhodamine B is a synthetic dye that banned for use and certified as a hazardous material according to Minister of Health of Indonesian Republic No. 376/Menkes/Per/1990 because it causes liver damage, kidney and lymph glands damage, followed with organ enlargement. The aim of this study is to identify Rhodamine B in lipsticks in the market. Samples were taken from 3 shops in Denpasar City and Badung Regency. Samples were soaked with amonia solution with using wool yarn to extract the rhodamine B dye and identification using TLC plate silica gel GF254 with n-butanol: ethyl acetate: amonia (1322:5.2:6.5) as mobile phase then detected with UV light 254 and $366 \mathrm{~nm}$. Identification by spectrophotodensitometry where the TLC plate was observed in the TLC Analyzer to observe the AUC in each spot formed. The AUC obtained from the instrument illustrates the concentration of the analyte in each bottle. The result shows that 3 examined samples doesn't contain rhodamine B.
\end{abstract}

Keywords: Rhodamin B, Lipstik, TLC, Spectrophotodensitometry

\section{PENDAHULUAN}

Kosmetika menjadi salah satu hal yang paling dekat dengan perempuan karena berperan penting untuk penampilan terutama riasan wajah. Lipstik merupakan salah satu kosmetika yang paling digemari oleh perempuan karena dapat memberi warna pada bibir. Kebutuhan akan lipstik di Indonesia mencapai angka 9,67\% dinilai dari perkembangan industri kecantikan per tahun 2017. Penambahan zat-zat tertentu yang dimanfaatkan untuk menunjang performa produk seperti pewarnaan. Survei menunjukkan warna sangat mempengaruhi keputusan konsumen dimana warna nude disukai hingga $80 \%$ dan colorful sebanyak $21,7 \%$. Oleh karena itu warna dapat mempengaruhi konsumen dalam pemilihan produk lipstik. Pada awalnya, 
pewarnaan dilakukan dengan menggunakan zat warna alami yang diperoleh pada tumbuhan, hewan, dan mineral, akan tetapi penggunaan zat warna tersebut menunjukkan tidak adanya kestabilan terhadap panas dan cahaya (Utami dan Suendi, 2008). Sehingga muncul keinginan produsen untuk tetap menguasai pangsa pasar akan tetapi dengan biaya yang relatif murah yakni dengan penambahan zat warna sintetik seperti rhodamin B.

Rhodamin B adalah salah satu pewarna sintetik yang dimanfaatkan dalam industri kertas dan tekstil. Rhodamin B dapat memberikan dampak negatif pada kesehatan seperti iritasi kulit dan saluran pernafasan. Rhodamin B adalah zat yang bersifat karsinogenik dan dalam kadar tang tinggi dapat menyebabkan kerusakan hati (Syakri, 2017). Penggunaan rhodamine B dinilai berbahaya bagi kesehatan dimana penumpukan rhodamine B di dalam tubuh dapat menyebabkan kerusakan organ tubuh hingga kematian. Berdasarkan efek toksik yang ditimbulkan sehingga diperlukan adanya suatu analisis senyawa tersebut dalam lipstik.

Analisis kualitatif dan kuantitatif pada senyawa rhodamin $\mathrm{B}$ telah dilakukan sebelumnya dengan menggunakan HPLC, spektofotometri UV-Vis dan elektroforesis kapiler. Dalam hal ini penggunaan KLTSpektrofotoensitometri adalah salah satu pilihan metode yang penting dikarenakan pelaksanaannya yang dapat dilakukan secara sederhana dan simultan sehingga membutuhkan waktu yang lebih singkat. Analisis dengan KLTSpektrofotodensitometri mampu memisahkan komponen-komponen sampel berdasarkan perbedaan kepolarannya dan secara kuantitatif dapat dihitung melalui densitasnya. Penelitian ini dilaksanakan untuk mendapatkan metode yang mampu digunakan untuk identifikasi senyawa serta penetapan kadar rhodamin B dalam lipstik berwarna merah dengan menggunakan KLTSpektrofotodensitometri.

\section{MATERI DAN METODE}

\section{Bahan}

Beberapa alat yang digunakan adalah labu takar (Pyrex), corong kaca, timbangan analitik, tabung reaksi (Pyrex), Erlenmeyer (Pyrex), batang pengaduk (Pyrex), sendok tanduk, pipet tetes, gelas ukur (Pyrex), gelas kimia (Pyrex), benang wol, kertas saring (Whatman No. 1), oven, hot plate, lempeng kromatografi lapis tipis (Merck), chamber
(Pyrex), TLC Auto Sampler (Camag), TLC Visualizer (Camag) dan TLC Analyzer (Camag).

\section{Alat}

Bahan-bahan yang digunakan adalah 3 lipstik berwarna merah yang dijual bebas di yaitu kota Denpasar dan kabupaten Badung, etanol 70\% (Merck), asam asetat (Merck), etil asetat (Merck), n-butanol (Merck), aquades, larutan $\mathrm{HCl}$ (Merck), larutan amonia (Merck).

\section{Cara Kerja}

\section{Pembuatan Larutan Stok dan Seri}

Larutan baku rhodamin B dibuat dengan konsentrasi sebesar $200 \mathrm{ppm}$. Larutan seri dibuat dengan melakukan pemipetan pada larutan baku dengan konsentrasi larutan seri sebesar 50; 75; $100 ; 125 ; 150$ ppm. Pelarut yang digunakan pada pembuatan larutan stok dan seri adalah larutan $\mathrm{HCl} 0,1 \mathrm{~N}$.

\section{Ekstraksi}

Tahap ekstraksi dilakukan dengan menggunakan prosedur berdasarkan penelitian dari Mamoto dan Citraningtyas (2013). Sebanyak $1 \mathrm{~g}$ sampel ditempatkan dalam Erlenmeyer kemudian direndam menggunakan $10 \mathrm{~mL}$ amonia 2\% (ammonia dibuat dengan dilarutkan dalam etanol 70\%) selama semalaman. Penyaringan dilakukan menggunakan kertas saring whatman no. 1. Larutan dipindahkan ke dalam gelas beaker kemudian dipanaskan di atas hot plate. Residu penguapan dilarutkan dengan $10 \mathrm{~mL}$ larutan asam (dilakukan pencampuran 10 $\mathrm{mL}$ air dan $5 \mathrm{~mL}$ asam asetat $10 \%$ ). Benang wol dengan panjang $20 \mathrm{~cm}$ dimasukkan ke dalam larutan asam dan dididihkan hingga 10 menit, zat warna akan mewarnai benang wol, kemudian benang wol diangkat dan dicuci dengan akuades. Benang wol dimasukkan ke dalam larutan basa yaitu $10 \mathrm{~mL}$ amonia 10\% (ammonia dibuat dengan dilarutkan dalam etanol 70\%) dan didihkan. Benang wol akan melepaskan zat warna, zat warna akan masuk ke dalam larutan basa. Larutan basa yang didapat selanjutnya digunakan sebagai cuplikan sampel pada analisis KLT.

\section{Identifikasi dengan KLT}

Lempeng KLT berukuran $16 \times 10 \mathrm{~cm}$ dicuci dengan methanol kemudian diaktivasi dengan cara dipanaskan dengan oven pada suhu $100^{\circ} \mathrm{C}$ selama 10 menit. Sampel ditotolkan pada plat KLT menggunakan TLC Auto Sampler dengan jarak $2 \mathrm{~cm}$ dari bagian bawah plat, jarak antar 
noda adalah $1 \mathrm{~cm}$. Kemudian diangin-anginkan beberapa saat hingga mengering. Plat KLT yang telah mengandung cuplikan dimasukkan ke dalam chamber yang telah dijenuhkan dengan fase gerak berupa n-butanol : etil asetat : amonia $(13,2: 5,2: 6,5)$. Dibiarkan hingga plat terelusi, kemudian lempeng KLT diangkat dan dikeringkan. Pengamatan warna dilakukan secara visual serta di bawah sinar UV pada TLC Visualizer, jika secara visual noda terlihat berwarna merah jambu dan d ibawah sinar UV
$254 \mathrm{~nm}$ dan $366 \mathrm{~nm}$ berfluoresensi kuning atau orange, maka menunjukkan adanya rhodamin B.

\section{Identifikasi dengan Spektrofotodensitometri}

Plat KLT selanjutnya diamati pada $T L C$ Analyzer untuk diamati AUC pada masingmasing spot yang terbentuk. AUC yang diperoleh dari instrumen tersebut menggambarkan konsentrasi analit pada masingmasing totolan.

\section{HASIL DAN PEMBAHASAN}

\section{Pembacaan Simulasi dan Sampel}

Tabel 1. Hasil Pembacaan Simulasi Sampel

\begin{tabular}{lccl}
\hline Larutan & Rf & AUC & Keterangan \\
\hline Standar & 0.77 & 2893.5 & Rhodamin B \\
Seri 1 & 0.76 & 636.6 & Rhodamin B \\
Seri 2 & 0.76 & 793.4 & Rhodamin B \\
Seri 3 & 0.76 & 1240.4 & Rhodamin B \\
Seri 4 & 0.75 & 1460.2 & Rhodamin B \\
Seri 5 & 0.75 & 696.0 & Rhodamin B \\
Sampel 1 & 0.74 & 1460.8 & Rhodamin B \\
Sampel 1 & 0.74 & 1558.3 & Rhodamin B \\
Sampel 1 & 0.75 & 1502.7 & Rhodamin B \\
Sampel 2 & 0.75 & 1275.7 & Rhodamin B \\
Sampel 2 & 0.75 & 1037.6 & Rhodamin B \\
Sampel 2 & 0.75 & 1516.3 & Rhodamin B \\
Sampel 3 & 0.76 & 1768.9 & Rhodamin B \\
Sampel 3 & 0.76 & 2091.4 & Rhodamin B \\
Sampel 3 & 0.77 & 1659.0 & Rhodamin B \\
\hline
\end{tabular}

Tabel 2. Hasil Pembacaan Sampel

\begin{tabular}{lccc}
\hline \multicolumn{1}{c}{ Larutan } & Rf & AUC & Keterangan \\
\hline Standar & 0.79 & 3002.4 & Rhodamin B \\
Seri 1 & 0.79 & 716.8 & Rhodamin B \\
Seri 2 & 0.79 & 1044.2 & Rhodamin B \\
Seri 3 & 0.79 & 1245.8 & Rhodamin B \\
Seri 4 & 0.79 & 1578.3 & Rhodamin B \\
Seri 5 & 0.78 & 777.6 & Rhodamin B \\
Sampel 1 & 0.26 & 347.9 & unknown * \\
Sampel 1 & 0.26 & 296.5 & unknown * \\
Sampel 1 & 0.26 & 260.2 & unknown * \\
Sampel 2 & 0.18 & 235.6 & unknown * \\
Sampel 2 & 0.26 & 316.5 & unknown * \\
Sampel 2 & 0.26 & 300.4 & unknown * \\
Sampel 3 & 0.27 & 884.3 & unknown * \\
Sampel 3 & 0.27 & 450.5 & unknown * \\
Sampel 3 & 0.28 & 808.7 & unknown * \\
\hline
\end{tabular}




\section{Analisis Kualitatif}

Tabel 3. Hasil Analisis Kualitatif

\begin{tabular}{|c|c|c|c|}
\hline Sampel & $\begin{array}{c}\text { Warna } \\
\text { Awal }\end{array}$ & $\begin{array}{c}\text { Warna Saat } \\
\text { Pencahayaan }\end{array}$ & Ket. \\
\hline A & Ungu & $\begin{array}{l}\text { Tidak } \\
\text { Berfluorosensi }\end{array}$ & Negatif \\
\hline B & $\begin{array}{l}\text { Merah } \\
\text { Muda }\end{array}$ & Berfluorosensi & Positif \\
\hline $\mathrm{C}$ & $\begin{array}{l}\text { Merah } \\
\text { Kekuni } \\
\text {-ngan }\end{array}$ & $\begin{array}{l}\text { Tidak } \\
\text { Berfluorosensi }\end{array}$ & Negatif \\
\hline
\end{tabular}

\section{Validasi Metode}

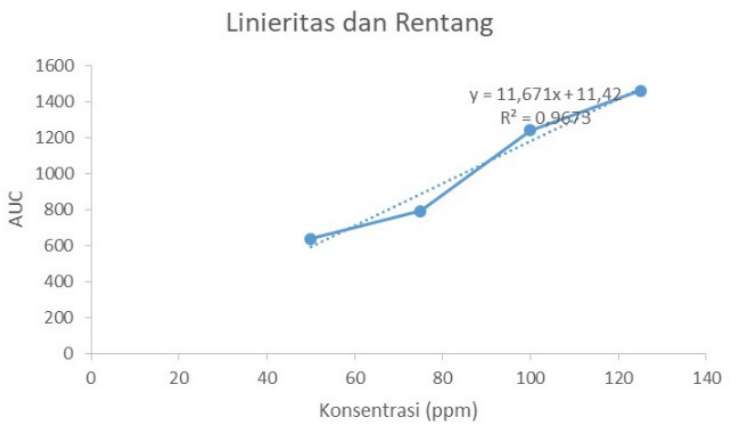

Gambar 1. Linieritas dan Rentang

Kosmetika merupakan bahan atau sediaan yang dimanfaatkan untuk mempercantik diri salah satunya adalah lipstik. Penggunaan yang sangat banyak di masyarakat khususnya kalangan perempuan mendorong produsen untuk membuat sediaan lipstik yang mempertahankan warnanya dala waktu yang lama. Pewarna yang sering disalahgunakan produsen adalah Rhodamin B. Rhodamin adalah salah satu zat warna golongan xhantenes dyes yang kegunaannya diterapkan sebagai pewarna merah pada industri tekstil dan plastik. Pemanfaatan Rhodamin B dalam kosmetika tidak diperbolehkan sesuai peraturan yang tercantum dalam Peraturan Menteri Kesehatan RI No. 445/MenKes/Per/V/1998 yang mencakup tentang zat warna yang termasuk dalam bahan berbahaya. Penggunaan Rhodamin B dapat mengiritasi saluran pernapasan dan penumpukannya dapat menyebabkan gangguan fungsi hati berupa kanker dan tumor hati.
Tabel 4. Hasil Penetapan Kadar Larutan

\begin{tabular}{|c|c|c|c|}
\hline Larutan & $\begin{array}{l}\text { Kadar } \\
(\text { ppm) }\end{array}$ & AUC & $\begin{array}{c}\text { Kadar } \\
\text { Totolan } \\
\text { (ppm) }\end{array}$ \\
\hline Seri 1 & 50 & 636,6 & 250 \\
\hline Seri 2 & 75 & 793,4 & 375 \\
\hline Seri 3 & 100 & 1240,4 & 500 \\
\hline Seri 4 & 125 & 1460,2 & 625 \\
\hline Seri 5 & 150 & 696,0 & 750 \\
\hline Simulasi & 109 & 1460,8 & 545 \\
\hline \multirow[t]{2}{*}{1} & 109 & 1558,3 & 545 \\
\hline & 109 & 1502,7 & 545 \\
\hline Simulasi & 98 & 1275,7 & 480 \\
\hline \multirow[t]{2}{*}{2} & 98 & 1037,6 & 480 \\
\hline & 98 & 1516,3 & 480 \\
\hline Simulasi & 89 & 1768,9 & 445 \\
\hline \multirow[t]{2}{*}{3} & 89 & 2091,4 & 445 \\
\hline & 89 & 1659,0 & 445 \\
\hline \multicolumn{4}{|c|}{ Tabel 5. Hasil Validasi Metode } \\
\hline Larutan & $\begin{array}{c}\text { Kadar } \\
(\mathbf{p p m})\end{array}$ & Presisi & Akurasi \\
\hline $\begin{array}{c}\text { Simulasi } \\
1\end{array}$ & $\begin{array}{c}620 \\
662,69 \\
638,87\end{array}$ & $3,34 \%$ & $117,53 \%$ \\
\hline $\begin{array}{c}\text { Simulasi } \\
2\end{array}$ & $\begin{array}{c}541,624 \\
439,62 \\
644,698\end{array}$ & $18,92 \%$ & $121,79 \%$ \\
\hline $\begin{array}{c}\text { Simulasi } \\
3\end{array}$ & $\begin{array}{c}752,91 \\
891,074 \\
705,831 \\
\end{array}$ & $12,29 \%$ & $176,02 \%$ \\
\hline
\end{tabular}

Pengambilan sampel dilakukan secara acak berdasarkan area (Cluster Random Sampling) yang mana sampel diambil dari daerah Denpasar dan Badung dengan merk yang berbeda. Sebelum melakukan penetapan kadar Rhodamin B dalam sampel-sampel tersebut, dilakukan validasi metode terlebih dahulu. Validasi metode yang dilakukan meliputi presisi, akurasi, linieritas, LOD, dan LOQ. Data hasil validasi metode dapat dilihat pada Tabel 5 .

Berdasarkan data yang telah didapatkan, nilai presisi dan akurasi yang didapatkan tidak memenuhi persyaratan sehingga metode yang digunakan dapat dikatakan belum valid jika digunakan untuk uji kuantifikasi. Namun, jika dilakukan uji kualifikasi, metode dapat digunakan karena terbukti mampu menarik analit berupa Rhodamin B dari eksipiennya dalam simulasi lipstik yang dibuat untuk tujuan penelitian. 
Validasi metode yang diperoleh belum memenuhi standar yang telah dipersyaratkan, salah satu faktor penyebabnya adalah pada proses ekstraksi Rhodamin B. Simulasi lipstik yang dibuat diekstraksi dengan metode yang tedapat dalam jurnal Mamoto dan Citraningtyas (2013). Proses dalam ekstraksi yang memiliki risiko kesalahan yang tinggi adalah pada saat pemanasan atau penguapan. Jumlah total simulasi lipstik yang digunakan adalah 9 sampel dan semua sampel ini seharusnya diuapkan atau dipanaskan dalam waktu yang bersamaan karena dalam metodenya, tidak ditetapkan suhu dan waktu yang akan digunakan untuk menguapkan atau memanaskan sampel. Hal ini berdampak pada berbedanya waktu yang digunakan sehingga volume dari masing-masing larutan berbeda dan mempengaruhi perhitungan konsentrasi awal dari sampel tersebut. Namun, metode ini terbukti mampu menarik analit berupa Rhodamin B dalam simulasi sampel, dilihat dari adanya bercak merah muda pada $0.74-0.77$ yang mendekati Rf standar Rhodamin yaitu 0.77 pada plat KLT yang digunakan.

Setelah diterapkan metode uji pada ketiga sampel yang disiapkan, didapatkan hasil negatif untuk kandungan Rhodamin B pada lipstik tersebut. Hasil ini sudah sesuai dengan ketentuan pada Peraturan Menteri Kesehatan RI No. 445/MenKes/Per/V/1998 Tentang Zat Warna Tertentu yang Dinyatakan sebagai Bahan Berbahaya yang menyatakan bahwa pada produk kosmetik tidak boleh mengandung senyawa Rhodamin B.

\section{SIMPULAN DAN SARAN}

\section{Simpulan}

Berdasarkan penelitian yang dilakukan diperoleh bahwa ketiga sampel lipstik yang dianalisis tidak mengandung rhodamin $\mathrm{B}$ (negatif). Namun, metode ini terbukti mampu menarik analit berupa rhodamin B dalam simulasi sampel, dilihat dari adanya bercak merah muda pada $0.74-0.77$ yang mendekati Rf standar rhodamin yaitu 0.77 pada plat KLT yang digunakan. Validasi metode yang dilakukan dalam penelitian ini belum memenuhi standar yang telah dipersyaratkan. Persentase perolehan kembali yang didapatkan adalah sebesar 117,53 $176,02 \%$, sedangkan nilai RSD sebesar 3,34$18,92 \%$.

\section{Saran}

Penelitian ini perlu disempurnakan agar didapatkan metode analisis kandungan Rhodamin B dalam lipstik dengan metode KLTspektrofotodensitometri yang persyaratan validasinya terpenuhi, oleh karena itu, disarankan agar semua parameter dalam metode seperti waktu dan suhu pemanasan serta panjang benang wol yang digunakan selama proses penelitian ditentukan dengan pasti sehingga tidak menimbulkan variasi perlakuan terhadap sampel.

\section{DAFTAR PUSTAKA}

Mamoto, L. V., dan F. G. Citraningtyas. 2013. Analisis Rhodamin B Pada Lipstik Yang Beredar Di Pasar Kota Manado. Pharmacon 2 (2): 61-66.

Menkes RI. 2010. Peraturan Menteri Kesehatan Republik Indonesia Nomor 1175/Menkes/Per/VIII/2010 Tentang Izin Produksi Kosmetika. Jakarta: Menteri Kesehatan Republik Indonesia.

Syakri, Syamsuri. 2017. Analisis Kandungan Rhodamin B Sebagai Pewarna pada Sediaan Lipstik Impor yang Beredar di Kota Makassar. JF FIK UINAM $5(1): 40-45$.

Utami, W. dan Suhendi, A. 2009. Analisis Rhodamin B dalam Jajanan Pasar dengan Metode Kromatografi Lapis Tipis. Jurnal Penelitian Sains dan Teknologi 10(2):148-155. 